\title{
PROJETO DE MÓVEIS SOB MEDIDA: QUALIDADE NA PRODUÇÃO E NO USO SOB O DESIGN SUSTENTÁVEL
}

\author{
SOUZA, Paloma Ribeiro \\ Universidade Federal de Uberlândia, palomaribeirodsouza@gmail.com
}

\begin{abstract}
RESUMO
Atualmente, é possivel perceber que as condições econômicas, as necessidades dos indivíduos e a modificação nos hábitos de vida contribuíram para as alterações dos espaços residenciais. Existe uma crescente redução nas áreas úteis das moradias, que visam aumentar o lucro das empresas de construção civil, a despeito da qualidade da moradia do usuário. Diante deste cenário, visando a qualidade do morar, o mobiliário sob medida pode ser um aliado na organização dos espaços internos. Observando o outro lado, do ponto de vista da fabricação, o mesmo tem apresentado problemas devido ao volume de resíduos gerado no processo produtivo. O objetivo desse trabalho foi discutir e propor soluções no mobiliário sob medida oferecendo qualidade nos projetos, focando nas necessidades do usuário, com uma produção baseada nos princípios do design sustentável, para redução de impactos ambientais. A metodologia do estudo foi a de natureza exploratória e qualitativa, baseada em revisão de literatura associada a métodos de processos projetuais do design. Como resultados, foram criadas propostas de diretrizes projetuais com o intuito melhorar a qualidade do mobiliário tanto na produção quanto para o usuário. Este estudo apresenta parte dos resultados alcançados em um trabalho de conclusão do curso de Design UFU finalizado em 2017.
\end{abstract}

Palavras-chave: Móveis sob Medida, Customização, Qualidade de Fabricação, Qualidade do Morar, Design sustentável.

\begin{abstract}
Today, it is possible to perceive that the economic conditions, the needs of the individuals and the modification in the habits of life contributed to the alterations of the residential spaces. There is an increasing reduction in the useful areas of housing, which aim to increase the profit of construction companies, despite the quality of the housing of the user. Given this scenario, aiming at the quality of housing, bespoke furniture can be an ally in the organization of internal spaces. Looking at the other side, from the manufacturing point of view, it has presented problems due to the volume of waste generated in the production process. The objective of this work was to discuss and propose solutions in the furniture to measure offering quality in the projects, focusing on the needs of the user, with a production based on the principles of sustainable design, to reduce environmental impacts. The methodology of the study was of an exploratory and qualitative nature, based on a review of the literature associated to methods of design processes. As a result, proposals for design guidelines were created with the aim of improving the quality of the furniture both in production and for the user. This study presents part of the results achieved in a UFU Design course completed in 2017.
\end{abstract}

Keywords: Móveis sob Medida, Customização, Qualidade de Fabricação, Qualidade do Morar, Design sustentável.

SOUZA, P. R. Projeto de móveis sob medida: qualidade na produção e no uso sob o design sustentável. In: SIMPÓSIO BRASILEIRO DE QUALIDADE DO PROJETO NO AMBIENTE CONSTRUÍDO, 6., 2019, Uberlândia. Anais... Uberlândia: PPGAU/FAUeD/UFU, 2019. p. 213-221. DOI https://doi.org/10.14393/sbqp19021. 


\section{INTRODUÇÃO}

As moradias e as formas do morar atuais, têm sido foco de pesquisas na busca de uma compreensão de questões relacionadas a qualidade física e subjetiva no uso dos espaços.

Quanto às questões físicas, pode-se ressaltar a diminuição das medidas dos ambientes, que na maioria das vezes, não acomodam os móveis de produção seriada, que são disponíveis nos mercados de forma adequada, assim como a baixa qualidade dos materiais de acabamento oferecidos pelos mesmos.

Analisando as questões subjetivas, a qualidade aparece em conjunto com outros termos tais como: privacidade no meio interno e externo da moradia; flexibilidade dentro dos ambientes e como ela pode ser garantida; aspectos do morar, que trata do modo como o usuário se identifica com o espaço; e o comportamento, que aparece em conjunto com a forma de apropriação daquele local.

Analisando ainda o lado subjetivo, outro fator dê influencia, é a compra do imóvel próprio, incentivado culturalmente no Brasil. Fator este, que estimula o mercado de construção civil a produzir moradias sem se preocupar com aspectos qualitativos do morar.

Com base no sistema descrito, para estudo do espaço, foram selecionados os apartamentos do projeto Minha Casa Minha Vida (MCMV)', a fim de entender e propor possíveis soluções para melhorar a qualidade de vida do usuário dentro dessas "habitações mínimas" através do projeto de móvel sob medida, produzido sob a ótica do design sustentável.

\section{FUNDAMENTAÇÃO}

\subsection{Produção moveleira: industrial $x$ seriada}

Observando o crescimento no setor de móveis seriados ao longo dos anos, é possível perceber um avanço tecnológico com a introdução de novas máquinas para auxiliar as produções industriais. Porém, junto com elas houve dois fatores que podem ser considerados problemáticos: o ciclo de vida dos produtos diminuiu, aumentando o consumo dos móveis e o descarte dos materiais, além do fato de não existir um estudo para criação de produtos que atendam às necessidades dos usuários e os espaços em que serão colocados. (ROSA et al., 2007).

Folz (2003) acredita que no setor mobiliário os produtos têm sido desenvolvidos para serem baratos, porém muito independentes da habitação, como qualquer outro produto industrial, sem pensar na funcionalidade ou adequação do mesmo no espaço.

No Brasil, pode-se dizer que a produção industrial ou seriada de móveis foi dividida em duas etapas: a) a primeira na década de 1930, quando os móveis seguiam fielmente as tradições coloniais e europeias sendo apenas cópias, e b) a segunda após essa data, com o surgimento da arquitetura moderna no país. (DEVIDES; 2006). 
Os móveis industriais são produzidos a partir de cortes em chapas de forma seriada que já possuem comandos para saírem cada parte do móvel pronta, todas padronizadas em medidas. Dessa forma, o mobiliário final possui suas dimensões fixas, sem uma opção de reajuste, se necessário. É importante lembrar ainda que, mesmo com todo esse processo industrial e padronizado, o descarte de material não é reduzido, continuando a existir em grandes volumes. O móvel é visto como um produto que precisa ser barato, não importando a distorção que possa existir entre a proporção de seus volumes e os espaços aos quais estão destinados. (FOLZ; 2003; P. 102).

Já o setor de móveis sob encomenda, também denominado móveis sob medida, fabrica produtos personalizados, criados através das necessidades específicas e demandas dos usuários. Esse ramo de negócio cresceu nos últimos anos devido à inserção do design e à flexibilidade quanto à personalização dos móveis, juntamente com as questões dos espaços reduzidos nas moradias. São móveis fabricados geralmente em marcenarias, que se configuram como micro e/ou pequenas empresas, em geral, familiares, que trabalham de forma artesanal. O sistema sob medida não possui estoque e por este motivo a aquisição de materiais para produção é realizado no fechamento do projeto, reduzindo o poder de barganha e financiamento dos materiais, bem como o gerenciamento do negócio (SCHUSTER, 2013).

Os móveis sob encomenda, por possuírem uma facilidade de personalização, geram, durante sua produção, uma quantidade de resíduos que estará relacionada com a forma escolhida para a fabricação: material, processo, tecnologia envolvida, tipo de corte. Assim ele se ajusta não somente às necessidades do usuário, como também nos processos de fabricação. (AZEVEDO, 2011 apud SCHUSTER, 2013).

Para as empresas de móveis, a expressão móvel planejado, vem designar um produto de peças soltas, que se adequam e personalizam um espaço específico, de acordo com a necessidade do usuário. (GOUVEIA, 2012 apud BARBOSA, 2013).

\subsection{Customização de massa}

A customização de massa surgiu pelo fato de as empresas não conseguirem acompanhar as rápidas mudanças no mercado e 0 consequente encurtamento do ciclo de vida dos produtos. Aparece, assim, como um aperfeiçoamento dos processos tradicionais existentes e com um produto que consegue acompanhar os custos competitivos e qualidade, oferecendo também uma maior flexibilidade aos usuários (LAU,1995; SVENSSON; BARFORD,2002) apud VIGNA; MIYAKE,2009).

Pires (2004, apud VIGNA; MIYAKE,2009), apresenta quatro definições de estratégias produtivas:

- Produção para estoque (MTS - Make to Stock): caracterizada pela produção de bens a partir da previsão das demandas, com estoques pré-existentes de produtos não customizados: tem a vantagem de explorar a economia de escala com baixo custo de produção e rapidez na entrega do produto; 
- Montagem sob encomenda (ATO - Assemble to Order): caracterizada pela manutenção de estoques de subconjuntos, componentes e materiais diversos até o recebimento do pedido do cliente, contendo as especificações do produto final; porém, dificulta a influência por parte da empresa na concepção do projeto final;

- Produção sob encomenda (MTO - Make to Order): caracteriza-se pela interação do cliente com o produto, podendo participar ativamente no desenvolvimento do projeto básico do produto desejado, auxiliando ainda nas questões de diminuição de estoques;

- Engenharia sob encomenda (ETO - Engineer to Order): extensão do MTO, em que o projeto do produto é elaborado com grande interação com o cliente. É a melhor opção em termos de customização, oferecendo mais liberdade de escolha ao usuário final.

\subsection{Modularidade}

Outra forma de trazer interação do mobiliário oferecido com o ambiente do usuário, é através do uso da modularidade, que é definida como uma estratégia para organizar produtos e processos complexos para economizar recursos (Baldwin; Clark, 2000). A modularidade consiste em desenvolver produtos para serem compostos através da adição, remoção ou substituição de um ou mais módulos focando nas necessidades do cliente (SIMPSON, 2004).

Os móveis modulares podem ser flexíveis quando se trata de várias funções e quando são reguláveis, o que auxilia na construção de espaços com mais desempenhos e até mesmo nas questões de privacidade.

O móvel pode ser expandido em dimensões que lhe permitam
até mesmo ser usado como um divisor de ambientes podendo
ser mais ou menos vazado, e ser composto conforme as
exigências do ambiente, como dormitório ou sala, por
exemplo. (FOLZ, 2003, P.141).

De modo geral, é possível observar que os produtos modulares trazem maiores benefícios para a empresa auxiliando em questões como estoque, maior aproveitamento do material na produção, oferecendo a oportunidade de customização do móvel para o cliente, mesmo que com pequenas modificações no produto.

Os produtos modulares podem ser divididos de duas formas:

- Modular: onde um ou mais elementos compõem a estrutura do produto final;

- Integral: onde se verifica uma maior complexidade na composição dos elementos funcionais ou em suas interfaces na construção da estrutura do produto. Sendo que dentro desta categoria, pode-se formar "famílias" de produtos que são criadas a partir da modificação de variáveis em uma ou mais dimensões, para aumentar ou diminuir a plataforma e viabilizar produtos com desempenhos diferentes que atendam as demandas específicas de cada segmento de mercado. (SIMPSON, 2004). 
De modo geral, é possível observar que os produtos modulares trazem maiores benefícios para a empresa no auxílio em questões como estoque, maior aproveitamento do material na produção, além de oferecer a oportunidade de customização do móvel para o cliente, mesmo que com pequenas modificações no produto. Para o cliente além de um acompanhamento maior na fabricação do produto, se torna possível a compra de um móvel que atenderá suas necessidades específicas e que de adeque melhor ao seu ambiente. A modularidade também trabalhará questões sustentáveis, já que otimizando as peças o descarte dos materiais durante o uso seria menor, pois se alguma parte do móvel é danificada, será possível trocar apenas aquela parte, sem perder o móvel como um todo.

\subsection{Design sustentável}

O design sustentável, pode contribuir de forma significativa na produção, buscando de forma ampla uma melhoria no produto final, aliando o menor desperdício de matéria prima no processo construtivo com aspectos ergonômicos e estéticos, conciliando o bem da empresa e a satisfação do usuário final.

Manzini e Vezzoli (2008) defendem que a sustentabilidade é um objetivo para se atingir ao longo dos anos até ser implantado totalmente no cotidiano vivido, e observando o lado dos processos projetuais. Dentre os aspectos mais abrangentes que devem ser considerados para o desenvolvimento de produtos mais sustentáveis, destacam-se: I) a busca por recursos sustentáveis e renováveis, com a otimização dos mesmos; II) o não acúmulo de lixo nos ecossistemas; e III) agir sempre respeitando os espaços naturais disponíveis. Os autores também estabelecem os requisitos básicos para que devem orientar a produção sustentável, como por exemplo: 1) criação dos projetos pensando no ciclo de vida do produto (desde sua pré produção até o descarte); 2) projetar levando em consideração o ciclo de vida desses produtos; 3) minimização dos recursos durante a execução; 4) executar através de recursos e processos que impactem menos o ambiente; 5) pensar na otimização e extensão da vida útil desses materiais. (MANZINI; VEZZOLI, 2008).

Assim, o design sustentável, de maneira ampla, atua como uma forma de melhorar o produto final, aliando o menor desperdício de matéria prima no processo de produção com aspectos como ergonomia e estética, visando o bem não apenas da empresa como também da satisfação do usuário final (FUNK et al., 2007).

Dentre as responsabilidades do designer industrial está a preocupação, no processo projetual, com o meio ambiente, por intermédio da escolha da matéria prima utilizada, da definição do processo de produção, da vida útil do produto. (FOLZ, 2003, P.132).

\section{METODOLOGIA}

O presente estudo é de natureza exploratória e qualitativa Gil (2008) baseada em revisão de literatura associada a métodos de processos projetuais. Quanto 
a elaboração do projeto a metodologia se baseia em métodos para desenvolvimento de produtos sustentáveis, apresentados por Lobach (2001), Munari (2008) principalmente na organização dos processos, observando também as especificações de Manzini e Vezzoli (2002) e Baxter (2003) para o entendimento, compreensão e solução dos problemas. O Quadro 1 mostra uma comparação entre os processos projetuais utilizados.

\section{Quadro 1 - Comparação dos processos projetuais de Lobach (2001) e Munari (2008)}

\begin{tabular}{|l|l|}
\hline Quadro Comparalivo dos Processos Projetuais \\
\hline Bern Lobach & Bruno Munari \\
\hline 1.FASE DE PREPARAÇÃO & (DP) Definição do problema \\
- Análise do problema & (CP) Componentes do problema \\
- Conhecimento do problema & (CD) Coleta de dados \\
- Coleta de informações & (AD) Análise de dados \\
- Análise de informações & (C) Criatividade \\
\hline $\begin{array}{l}\text { 2. Fase da Geração } \\
\text {-Alternativa do problema }\end{array}$ & $\begin{array}{l}\text { (MT) Materiais e tecnologias } \\
\text { (E) Experimentação } \\
\text { (M) Modelo }\end{array}$ \\
\hline $\begin{array}{l}\text { Corpo de texto do Artigo } \\
\text { 3. Fase de Avaliação } \\
\text { - Avaliação das alternativas do } \\
\text { problema }\end{array}$ & (V) Verificação \\
\hline $\begin{array}{l}\text { 4. Fase de Realização } \\
\text { Realização da solução do problema }\end{array}$ & (D) Desenho final \\
\hline
\end{tabular}

\section{RESULTADOS}

Como resultado inicial, foi possível alcançar uma lista de diretrizes baseado no design sustentável, para criação de um Sistema de mobiliário sob medidas baseadas nos conceitos e análises realizadas, esses compararam as necessidades do usuário e os parâmetros de fabricação por meio da personalização (SOUZA,2017). A proposta de diretrizes tem como intuito melhorar a qualidade do mobiliário para os residentes em moradias compactas de projetos como Minha Casa Minha Vida. Essas diretrizes são características e parâmetros a serem considerados na execução do projeto de mobiliário, sendo elas:

- Analisar as necessidades específicas do usuário, assim como, do espaço a ser inserido e as medidas possíveis para projetar o móvel;

- Escolher materiais e recursos com mínimo impacto ambiental;

- Possibilitar que peças e partes presentes no móvel sejam facilmente substituídas ou reparadas;

- Considerar a modularidade, facilitar a composição de partes e uso de outros materiais;

- Considerar a combinação de partes, permitir variadas composições, de forma a atender necessidades específicas funcionais, dimensionais e estéticas, assim o usuário tem maior possibilidade de participar nas escolhas do produto final;

- Utilizar mecanismos e encaixes que possibilitem a maior vida útil do produto, aqueles que facilitam a montagem e desmontagem; 
- Desenvolver desenhos com formas simples, pois facilitam a produção, minimizam os erros e diminuem os custos para elaboração;

- Considerar as dimensões das chapas aproveitando o máximo do material escolhido nos cortes, padronizando também medidas de componentes;

- Minimizar os resíduos e os gastos com energia durante a produção (SOUZA, 2017);

A partir das diretrizes propostas para o projeto, definiu-se um conjunto de móveis para quarto de apartamentos do MCMV que engloba guarda-roupas em três larguras: $170 \mathrm{~cm}, 110 \mathrm{~cm}$ e $56 \mathrm{~cm}$ e duas alturas diferentes: $255 \mathrm{~cm}$ e $200 \mathrm{~cm}$, podendo acrescentar um maleiro de $55 \mathrm{~cm}$ de altura (Figura 1) e criado mudo com 4 possibilidades de composição diferentes, entre portas e gavetas optando por rodapé ou rodízios (Figura 2). Esses tendo tais características: produzido com MDF, pela sua resistência, porém essa da marca Masisa (Fornecedora de chapas de madeira) por seus painéis serem certificados com rótulo ecológico da ABNT (SOUZA,2017). As peças serão elaboradas utilizando um site para auxílio no aproveitamento do corte, Placa Centro, disponibilizado pela Masisa. Para resolver a questão de puxadores, optou-se por recortes em partes do móvel, pois assim não será necessário acrescentar outro material e para o desenho foi definido um formato retilíneo com encaixes a 90은 (SOUZA, 2017).

Foi definido o uso de portas de abrir para maior aproveitamento do espaço interno para acomodar as peças de roupa. Os móveis possibilitam modificações do usuário em seus materiais, em partes definidas e adição de módulos considerando a ideia de peças disponíveis em estoque. Finalmente, para os encaixes optou-se o minifix, mecanismo de conexão que após inserido na peça, possibilita montagem e desmontagem sem desgaste do material (SOUZA, 2017).
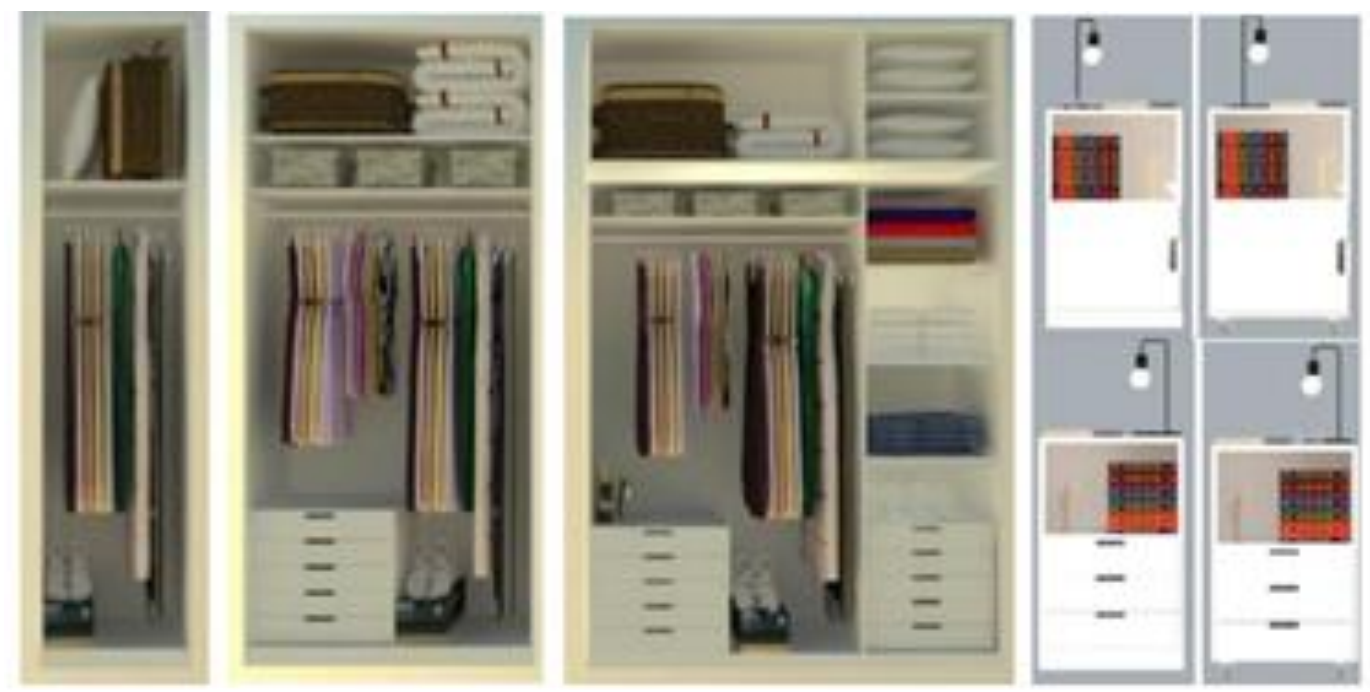

Figura 1- Opções de composição dos Guarda-roupas, Maleiro e Criados. Fonte: SOUZA (2017) 


\section{CONCLUSÃO}

Através dos resultados e análises alcançados, foi possível perceber que mesmo de forma simplificada, a indústria e os profissionais na área de projetos de móveis teriam a possibilidade de elaborar projetos e, consequentemente, produtos que cumprissem às necessidades de habitações mínimas de modo mais eficaz, evitando o desperdício de material e respeitando as questões sustentáveis.

A interação entre usuário e produção proposta aqui, possibilita uma personalização das peças tanto na funcionalidade quanto em questões estéticas e possibilita organizar o móvel a partir das necessidades exclusivas do usuário. Para aumentar essa interação e potencializar as sugestões, seria vantajoso a criação de um pequeno portfólio, esse com diferentes opções de composição das peças para escolha do cliente. O conjunto de móveis elaborados neste trabalho possui resoluções práticas para otimização no móvel pelo cliente, podendo ser alterados facilmente as prateleiras e cabideiros, assim como criado com gavetas ou porta.

Este trabalho também apresenta, como solução, uma lista de diretrizes, que pode funcionar como base bibliográfica e metodológica na construção de móveis em outros cenários similares, compreendendo que, no contexto atual, há uma falta de preocupação com o desperdício do material, principalmente pelos profissionais na elaboração dos móveis, sob medida, e a falta de possibilidade de alteração pelas indústrias na produção de modulares. Assim, esse documento pode auxiliar designers, decoradores e arquitetos que não consideram os pontos ressaltados nesta pesquisa e, dessa forma, não atuam dentro de uma lógica sustentável e não cumprem com um dever ético ambiental do profissional projetista de móveis.

\section{REFERÊNCIAS}

AZEVEDO, Patrícia Silva de; NOLASCO, Adriana Maria. Fatores de incorporação de requisitos ambientais no processo de desenvolvimento de produtos em indústrias de móveis sob encomenda. Ciência Rural - Universidade Federal de Santa Maria. RS. 2009.

BALDWIN, C.Y; CLARK, K.B (200); Managing in na age of modularity. In Gilmore, J.H; Pine II, J. B. Markets of one: creating customer- unique value through mass customization. Harvard Business Achool Press, Boston, MA.

BAXTER, Mike. Projeto de produto: guia prático para o design de novos produtos. São Paulo, SP: Edgard Blücher, 2003.

FOLZ, Rosana Rita. Mobiliário na habitação popular. 2002. 240f. Dissertação (Mestrado em Arquitetura em Urbanismo) Universidade de São Paulo, São Carlos- SP.

FOLZ, Rosana Rita. Mobiliário na habitação popular: discussões de alternativas para melhoria da habitabilidade. São Carlos: Rima, 2003.

GIL, Antonio Carlos. Como elaborar projetos de pesquisa. 4. ed. São Paulo: Atlas, 2008.

LOBACH, Bernd. Design industrial: base para a configuração dos produtos industriais. São Paulo: Blucher, 2001. 
MANZINI, EZIO; VEZZOLI, Carlo. O desenvolvimento de produtos sustentáveis: os requisitos ambientais dos produtos industriais. São Paulo: Editora da Universidade de São Paulo, 2008.

MUNARI, Bruno. Das coisas nascem coisas. 2.ed. São Paulo: Martins Fontes, 2008.

ROSA, Sergio Eduardo Silveira da; CORREA, Abidack Raposo; LEMOS, Mario Luiz Freitas; BARROSO, Deise Vilela. O setor de móveis na atualidade: uma análise preliminar. São Paulo: BNDES, São Paulo, 2007. Disponível em:

<www.bndes.gov.br>. Acessado em 11/05/2016.

SCHUSTER; Estefanie Moreira. Uma perspectiva sobre o design e a produção de móveis sob encomenda: uso e o descarte de painéis de fibra de madeira de média densidade. 2013. 212 f. Dissertação (Mestrado em Design) Universidade Federal do Paraná. Curitiba. PR.

SIMPSON, T.W. (2004); Product plataform design and customization: status na promise, Artificial Intelligence for Engineering Design, Analysis and Manufacturing, 18, 3-20.

SOUZA, Paloma Ribeiro de. Design sustentável: o projeto de móveis sob medida e sua importância para a qualidade da produção e do uso. Trabalho de Conclusão de Curso de graduação em Design. Faculdade de Arquitetura e Urbanismo e Design, Universidade Federal de Uberlândia.2017

VIGNA, Cláudio Marcos; MIYAKE, Dario IkUo. Capacitação do processo produtivo em uma empresa de alta tecnologia para customização em massa. Gestão da Produção, Operações e Sistemas - GEPROS. Ano 1, no 3 .2009. 